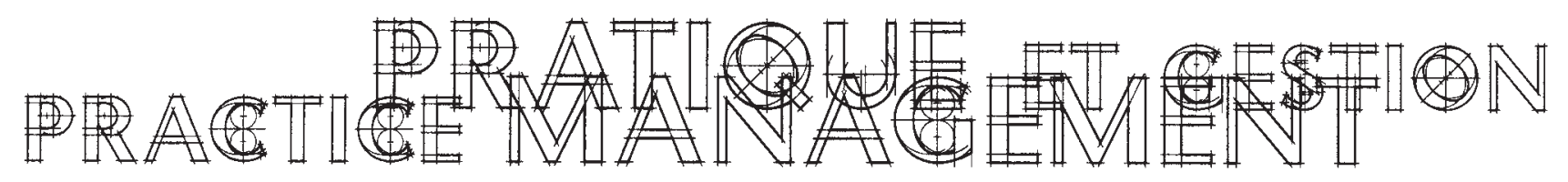

\section{Innovation Your Responsibility}

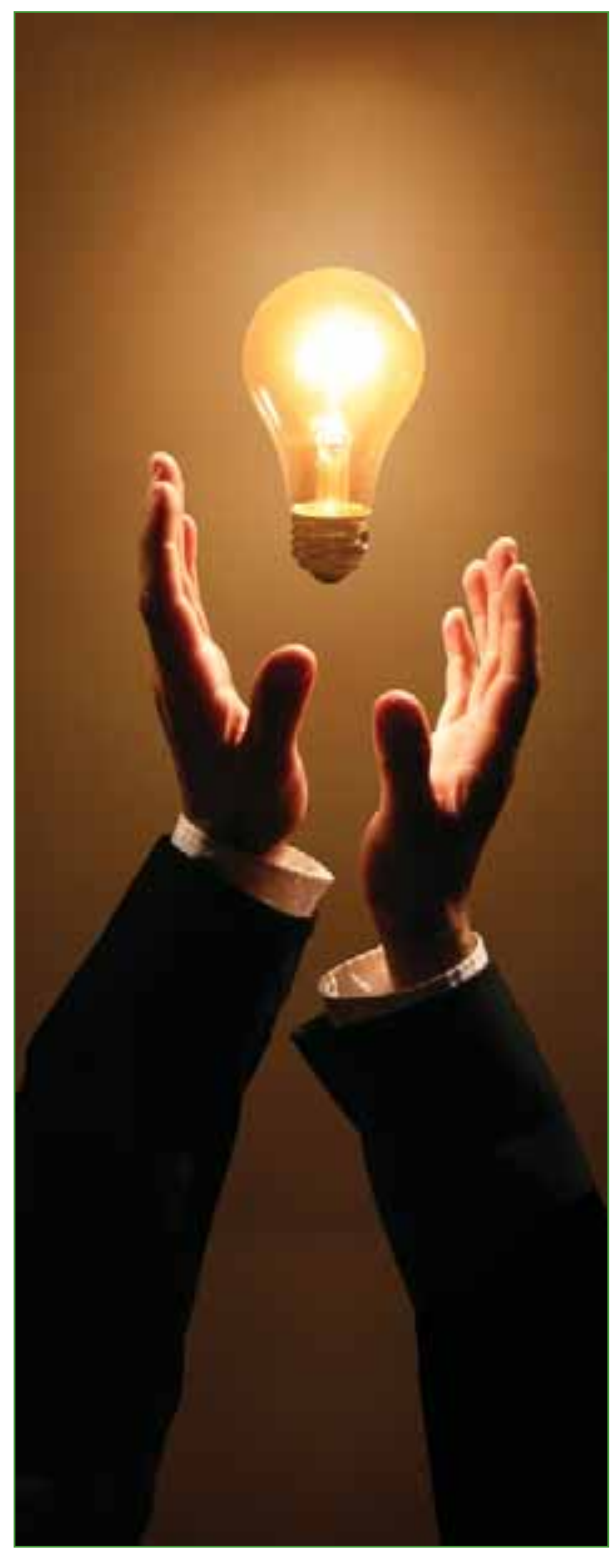

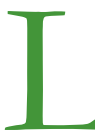

ike any business an optometric practice should always look for ways to improve the services it provides, the products that it sells and the processes in place to run the practice effectively. If you fall into complacency while your competitors continue to innovate, you will surely struggle and fall behind.

Although innovation can come from many sources, as the owner of the practice you have to take the lead and foster imaginative change. It starts with having an open mind to new ideas and thinking outside the box (which presumes that at some point you could think inside the box). You have to actively seek out these sources of change, sitting and waiting for that million-dollar idea to fall into your lap just won't do. Interaction with your colleagues and staff in a creative environment are logical first steps to seek new imaginative ideas. Patients themselves can be a source of inspiration but be careful for their feedback can often provide misleading information. As Henry Ford said, "If I asked my customers what they wanted, they'd have said a faster horse."

Change doesn't always have to happen in dramatic leaps and bounds. Sometimes small incremental changes (the "new and improved" scenario) over long periods of time can be just as effective. In fact, because our industry is basically a "mature" industry, developing radically new ways of doing things can be difficult. Optometrists are naturally conservative by nature so this slower pace of change suits us well.

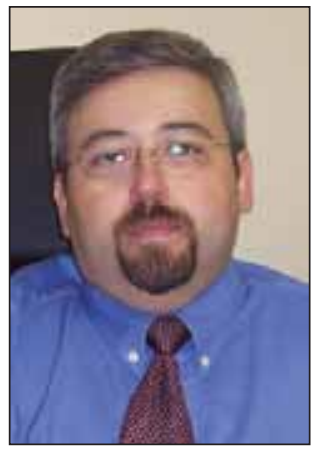

Alphonse Carew $\mathrm{BSC}, \mathrm{OD}, \mathrm{MBA}$ 


\section{PRACTICE MANAGEMENT

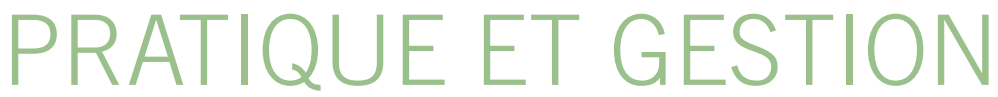

Most of your attention should be directed towards innovating the services you provide. This is the part of your practice you know best and where your optical competitors cannot follow. You have many sources from which to draw from, including continuing education seminars, trade shows, journals, your staff, and interactions with your colleagues both in person and online. Find out what the latest research is saying about new treatment modalities and think about how it might fit into your practice. The research may still be years away, but being ready for when it comes can put you at a significant advantage.

Laser corrective surgery co-management is a prime example of this. Optometrists who sought out this new service and introduced it early in their practice benefited greatly from the recognition in their community as being a leader in this field. Thankfully we live in a time where research is bringing new treatment regimes into doctors office faster than ever. You simply have to keep your "ear to the ground" and adapt these new technologies to your practice quickly.

Innovation in the products we sell (contact lenses, frames and lenses) often comes "gift wrapped" from our suppliers and their representatives. Manufacturers of these products spend a lot of money on research to make the better "mousetrap". Whether it's the most breathable contact lens or the progressive spectacle lens with the largest reading corridor you can easily adapt their technological enhancements to your practice and win the innovation race over your competitors.
Another area where you can look for innovation as a way to gain a competitive edge is in the way you manage your practice. There are plenty of great business ideas out there that can help you organize, train and reward your staff, hire and keep the best employees, as well as improve profitability and efficiency. Look outside the optometric community for sources of inspiration. Many years ago we merged our entire administration into one physical location. They now handle all incoming and outgoing calls, insurance issues, correspondence with patients and other professionals, scheduling, and recalls for four locations. All these tasks were once done at the front desk but now the receptionist can concentrate on our patients as they arrive and take care of their needs without any distraction. I got this idea from other industries and it has turned out wonderfully.

The final piece of the puzzle when it comes to being innovative is to make sure your patients know that you are constantly improving. Because they only see you once every year or two they may not know that you have the latest diagnostic equipment, or provide the best technology in contacts and glasses. You need to tell your patients at every point of contact. Include information in all outgoing literature and place it on your website.

Become the leader of innovative change in your practice and seek out new ideas from many varied sources. However, a good idea alone is not enough. You, along with your team, have to put these ideas into action. Nurture and reward innovation in your practice and you will reap the benefits.

This year we are proud to have completed a fully redesigned portfolio of lenses. The introduction of Proressiv PureLife in September and MyView earlier this year complete the portfolio. PureLife represents the most dramatic improvements and formula changes Rodenstock has ever done to a "classic" progressive lens. The standard parameters of progressive lenses have been designed based on average values for Pantoscopic Tilt, Vertex Distance, Frame Wrap and Pupil Distance which have not changed since the 1960s. Rodenstock has collected new information since 2000 with Impression lens orders. We have now taken this data and created a new set of standards for today's patients. PureLife will prove to outperform any other "classic" progressive lens design and only be outperformed by an individualized progressive that has the ability to be truly customized by individual parameters. Rodenstock will continue to be pioneers and lead with advancements in progressive lenses.

BRONZE PARTNER OF THE EYE HEALTH COUNCIL OF CANADA

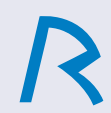

RODENSTOCK 